\title{
Influence of weak layers on the excavation-induced deformation of the surrounding rock in sub-sea tunnel
}

\author{
Lei Zhang \\ (International Education Center of Beijing Language and Culture University,100083, E-mail: \\ zhanglei1982@blcu.edu.cn)
}

Key words: weak layer; sub-sea tunnel; stability; surrounding rock

Abstract:This paper presents the analyses of the influence of the weak layers on the excavation-induced deformation in the sub-sea tunnel. The finite element software ABAQUS is adopted to investigate the stability of the surrounding rock in the case of inclined weak layers with various angles, and the stress and displacement fields of the surrounding rock are derived. The results show that the effects of the weak layer on the stability of the surrounding rock are more significant for a weak layer with smaller inclination angle. The weak layer has the largest influence on the stability of the tunnel when it located at the bottom of the tunnel.

\section{Introduction}

The stability of the surrounding rock in tunnels during the excavation is an important topic, including the strength and the deformation of the surrounding rock. The existence of the weak layer would have a great effect on the stability of the surrounding rock. It is observed that the tunnel is much more unstable when there is a weak layer, and this is particularly the case for the sub-sea tunnel. Thus, it is important to investigate the influence if the weak layer on the stability of the tunnel.

This paper considers the first sub-sea tunnel in China, and investigates the effects of weak layers on the stability of the tunnel by using numerical analyses. Various inclination angles locations of the weak layer are considered to determine the most unstable cases of the tunnel.

\section{Numerical Model and Validations}

The Xiangan tunnel in Xiamen is the first sub-sea tunnel in China. It is a three-hole tunnel. The two sides are the vehicular tunnel, and the middle one is the service tunnel, with a cross section of $16.8 \mathrm{~m}$ width and $14.6 \mathrm{~m}$ height. The mechanical parameters of soil layers are shown in Table 1. 
Table 1 Soil parameters

\begin{tabular}{cccccc}
\hline Layer & $\begin{array}{c}\text { Bulk } \\
\text { modulus } \\
(\mathrm{Mpa})\end{array}$ & $\begin{array}{c}\text { Shear } \\
\text { modulus } \\
(\mathrm{Mpa})\end{array}$ & $\begin{array}{c}\text { Friction } \\
\text { angle } \\
\left({ }^{\circ}\right)\end{array}$ & Cohesion (Mpa) & Poisson ratio \\
\hline $\begin{array}{c}\text { Filled } \\
\text { soil }\end{array}$ & 6.76 & 3.52 & 18 & 20 & 0.42 \\
Clay & 5.00 & 1.07 & 23 & 12 & 0.40 \\
Rock & 14.71 & 5.64 & 25 & 13 & 0.33 \\
Rock & 16.67 & 7.69 & 30 & 52 & 0.30 \\
\hline
\end{tabular}

The finite element software ABAQUS is adopted to investigate the stability of the surrounding rock. The size of the numerical model is $40 \mathrm{~m} \times 34 \mathrm{~m}$, and a permanent loading of $15 \mathrm{KPa}$ is applied at the top of tunnel. The calculated and the observed results are shown in Fig. 1, and a good agreement can be observed. The calculated value is slightly smaller than the observed one. This is likely due to that the total stress strength instead of the effective stress strength of the soil is adopted, and the influence of the temperature variation is not considered in the model.

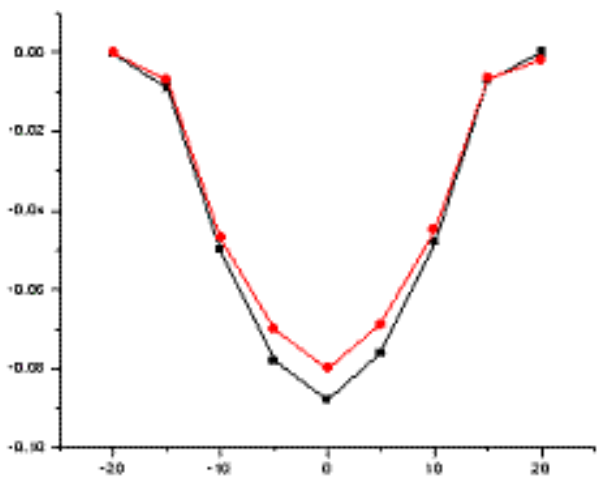

Fig. 1 The calculated and observed settlements at the ground surface

\section{The selection of different parameters}

The two-dimensional model of the tunnel is shown in Fig. 2. The weight of the seawater is exerted at the top of the model in terms of a uniform distributed load. 


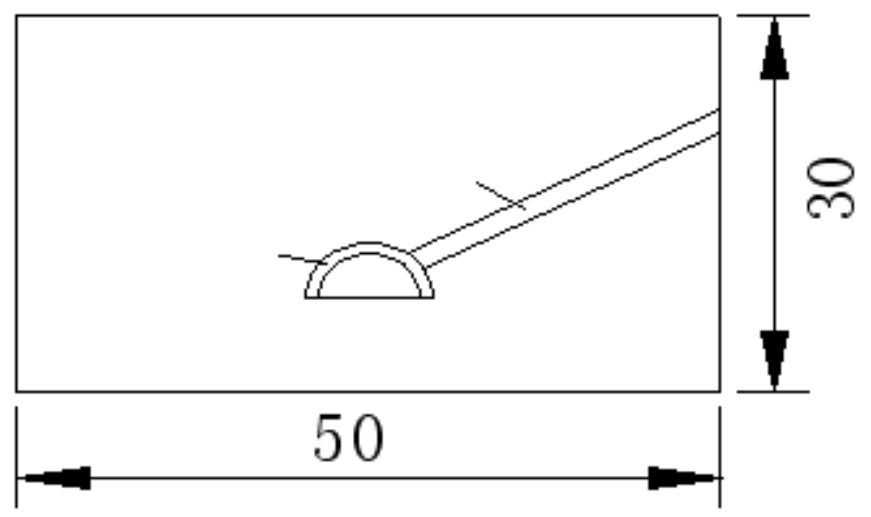

Fig. 2 Diagram showing the numerical model of the tunnel

Several assumptions are made in the simulation. The tectonic stress of the surrounding rock is neglected, and thus only the gravity stress of the surrounding rock is considered before the excavation. The model is assumed to be a plane-strain problem. The lining of the tunnel is considered to be elastic, and the volume expansion is neglected. In addition, the triangle element is adopted in the model, and a Tie connection is applied.

The depth of the water is taken as $40 \mathrm{~m}$, and the density of the seawater is $1.01 \mathrm{~kg} / \mathrm{m}^{3}$. The height and width of the rock are $30 \mathrm{~m}$ and 50 respectively, and the thickness of the weak layer is $2 \mathrm{~m}$. The Mohr-Coulomb model is applied for the surrounding rock and the weak layer. The tunnel is semi-circular with a diameter of $10 \mathrm{~m}$ and a depth of $15 \mathrm{~m}$. The thickness of the concrete lining is $0.4 \mathrm{~m}$. The boundary at the two sides is fixed in the horizontal direction. The boundary at the bottom is fixed in the vertical direction, and the rotation is constrained. The top of the model has a free boundary. Various cases are analyzed in terms of the location and inclination angle of the weak layer.

Table 2 physical and mechanical parameters of the material

\begin{tabular}{|l|l|l|l|l|l|}
\hline & $\begin{array}{l}\text { elastic } \\
\text { modulus } \\
(\mathrm{GPa})\end{array}$ & $\begin{array}{l}\text { Poisson } \\
\text { ratio }\end{array}$ & $\begin{array}{l}\text { Cohesion } \\
(\mathrm{Mpa})\end{array}$ & $\begin{array}{l}\text { Friction } \\
\text { angle }\left(^{\circ}\right)\end{array}$ & $\begin{array}{l}\text { Density } \\
\left(\mathrm{Kg} / \mathrm{m}^{3}\right)\end{array}$ \\
\hline $\begin{array}{l}\text { Surrounding } \\
\text { rock }\end{array}$ & 20 & 0.2 & 3 & 40 & 2300 \\
\hline Weak layer & 1 & 0.3 & 0.1 & 25 & 2200 \\
\hline Concrete & 28 & 0.17 & & & 2700 \\
\hline
\end{tabular}

\section{Results and Analyses}

Displacement of the surrounding rock

The vertical displacement for the case that is without the weak layer, with the weak layer at the 
bottom of the tunnel, and with a weak layer of various inclination angles are shown in Figs. 4-5. The maximum values of the vertical displacement for different cases are shown in Table. 3.

Table 3 The maximum value of the vertical displacement

\begin{tabular}{|l|l|l|l|l|l|l|l|}
\hline & Displacement & $15^{\circ}$ & $30^{\circ}$ & $45^{\circ}$ & $60^{\circ}$ & $75^{\circ}$ & $90^{\circ}$ \\
\hline $\begin{array}{l}\text { Top of } \\
\text { the tunnel } \\
\text { mm }\end{array}$ & 0.79 & 0.66 & 0.67 & 0.77 & 0.69 & 0.63 & 0.46 \\
\hline $\begin{array}{l}\text { Bottom } \\
\text { of the } \\
\text { tunnelmm }\end{array}$ & 1.55 & 0.40 & 0.39 & 0.36 & 0.33 & 0.31 & 0.29 \\
\hline
\end{tabular}

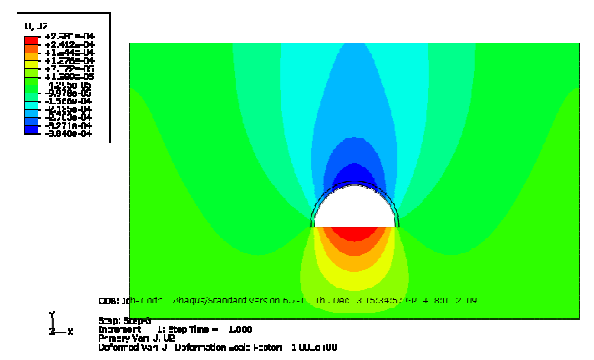

Fig 4 The vertical displacement without the weak layer

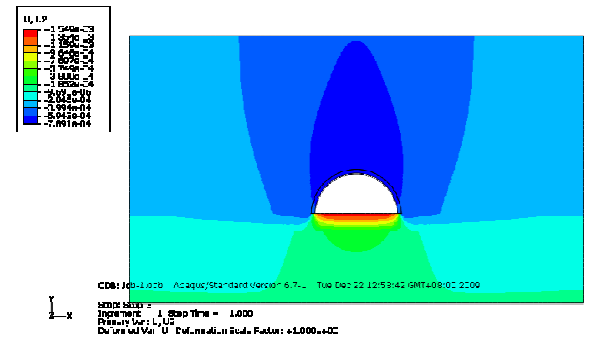

Fig 5 The vertical displacement with a weak layer at the bottom of the tunnel

It can be seen from Fig. 3 that the maximum displacement at the top of the tunnel is $0.79 \mathrm{~mm}$, corresponding to the case of $45^{\circ}$ inclination. The maximum displacement at the bottom of the tunnel is $1.55 \mathrm{~mm}$, when the weak layer is located at the bottom of the tunnel. The displacement at the bottom of the tunnel decreases with increasing the inclination angle; the displacement at the top of the tunnel increases with increasing the inclination angle, and the maximum displacement is $0.77 \mathrm{~mm}$ for the inclination angle of $45^{\circ}$, then the displacement decreases with increasing the angle. Thus, it is concluded that the effects of the weak layer on the stability of the tunnel decrease with the increase of the inclination angle of the weak layer. The existence of a weak layer with a $0^{\circ}$ inclination is the worst in terms of the stability of the tunnel.

\section{Stress of the surrounding rock}

The stresses without the weak layer and with a weak layer at the bottom of the tunnel are shown in Fig. 6 and Fig. 7. Observe the weak layer has the most significant effect when located at the bottom the tunnel. 


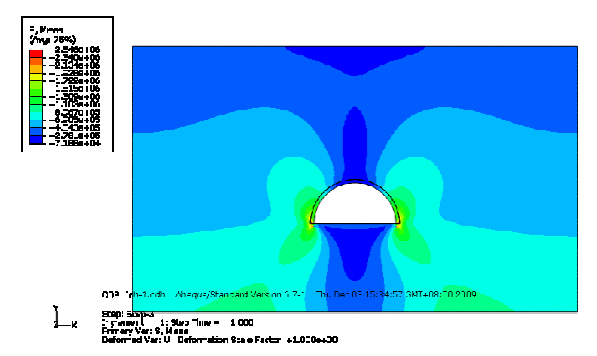

Fig. 6 The stress without the weak layer

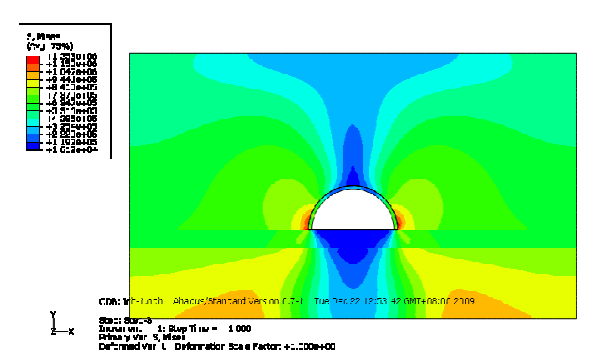

Fig 7 The stress with a weak layer at the bottom of the tunnel

\section{Conclusions}

(1) The existence of the weak layer would reduce the stability of the tunnel, and the inclination angle has a significant effect on the stability of the tunnel.

(2) The weak layer has the most significant effect on the tunnel when it located at the bottom the tunnel.

(3) The effects of the weak layer on the stability of the tunnel decrease with the increase of the inclination angle of the weak layer. The existence of a weak layer with a $0^{\circ}$ inclination is the worst case in terms of the stability of the tunnel.

\section{References}

[1]JIANG Y J, Yosihiko Tanabashi,LI Boetal.Influ-ence of Geometrical Distribution of Rock Joints on De-formational Behavior of Underground Openin[J].Tunnelling and Underground Space Technology, 2006, 2 (5): 485-491.

[2]DUAN Y Y, SONG H W, ZHAO J, et al. Numerical simulation of the influence of non-continuous structure of rock mass on the stability of tunnel [J]. Geotechnical engineering in China, 2004,7(9):34-35,39.

[3] WANG Z Q, WANG J X, ZHENG Y R, ZHANG N M. Limit analysis of subsea tunnel stability by finite element method in fault-rupture zone with water penetration. Chinese journal of rock mechanics and engineering.2007,26(2): 3751-3755. 